\title{
Incremental holistic controller
}

\author{
A. Weinmann OVE
}

The trace of inverse coefficient matrix method in state space is used to implement and simplify an iterative design of a control system with main interest in increasing dynamical performance quality or to check if stability danger exists. The $\tau$-locus is a helpful design element. Various applications and examples are presented for illustration.

Keywords: controller design; controller norm; chordal projection; $\tau$-locus plot; $\tau$-assignment

\section{Inkrementeller holistischer Regler.}

Die Methode der Spur der inversen Koeffizientenmatrix im Zustandsraum wird verwendet, den inkrementalen Entwurf eines Regelkreises zu besorgen und zu vereinfachen. Hauptinteresse liegt dabei darin, die dynamische Übertragungsqualität zu verbessern oder Stabilitätsgefahren aufzuzeigen. Der geometrische $\tau$-Ort der inversen Eigenwerte ist ein hilfreiches Entwurfselement. Verschiedene Anwendungen und Beispiele werden zur Veranschaulichung präsentiert.

Schlüsse/wörter: Reglerentwurf; Reglernorm; chordale Projektion; $\tau$-Wurzelort; $\tau$-Vorgabe

Received September 29, 2020, accepted February 3, 2021, published online February 23, 2021

(c) The Author(s) 2021

\section{Introduction. Influencing system dynamics. Stability} border and indicator. Discussion of $\tau$

The considerations are based on the elementary relations $\lambda_{i}\left[\mathbf{A}^{-1}\right]=$ $1 / \lambda_{i}[\mathbf{A}]$ and $\sum\left[\lambda_{i}\right]=\operatorname{tr}[\mathbf{A}]$, i.e., the trace of the system matrix in state space.

The term of holistic controller can be renamed in more detail by Trace of inverse matrix method, i.e., as specified in $[3,5]$,

$$
\tau \triangleq-\Sigma_{j}\left(1 / \lambda_{j}[\mathbf{A}]\right)=-\operatorname{tr}\left[\mathbf{A}^{-1}\right] .
$$

For the closed-loop control system with the output controller $\mathbf{K}_{\mathbf{y}}$ one has

$$
\operatorname{tr}\left[\left(\mathbf{A}+\mathbf{B} \mathbf{K}_{y} \mathbf{C}\right)^{-1}\right]+\mu\left\|\mathbf{K}_{y}\right\|_{F} \rightarrow \min _{\mathbf{K}},
$$

where the controller is utilized to approach a change of the control system dynamics. Executing the first derivative with respect to $\mathbf{K}$ and $\mathbf{K}_{y}$, for the state controller and for the output controller, one has, Eq. (17) and Eq. (18), respectively, and

$$
\begin{aligned}
-\mathbf{B}^{T}(\mathbf{A}+\mathbf{B K})^{-2 T}+2 \mu \mathbf{K} & =\mathbf{0} \\
-\mathbf{B}^{T}\left(\mathbf{A}+\mathbf{B K}_{y} \mathbf{C}\right)^{-2 T} \mathbf{C}^{T}+2 \mu \mathbf{K}_{y} & =\mathbf{0} .
\end{aligned}
$$

Holistic controller yields a proposal for the controller design improving the dynamic performance of the control system as far as stability and oscillation properties are concerned. An increment change in the state controller $\Delta \mathbf{K}=-\alpha \mathbf{B}^{T} \mathbf{A}^{-2 T}$ can be performed.

A norm-oriented $\tau$-(root)-locus is developed in what follows where the sum of eigenvalues of the $\mathbf{A}^{-1}$ matrix (not $\lambda_{i}[\mathbf{A}]$ ) are balanced versus the controller norm. A norm-limited output controller and the $\tau$-assignment is described as well.

The main idea is to use $\operatorname{tr}\left[\mathbf{A}^{-1}\right]$ or $\operatorname{tr}\left[(\mathbf{A}+\mathbf{B K})^{-1}\right]$ as a whole, and not the eigenvalues separate, and its gradient versus $\mathbf{K}$, corresponding to Eq. (17) or Eq. (18).

For stable systems, small (and positive) values of $\tau=-\operatorname{tr}\left[\mathbf{A}^{-1}\right]$ are desired for good dynamics, since then the eigenvalues $\lambda[\mathbf{A}]$ are negative big and far in the left. Combining both intentions leads to
Eq. (6) which is equated with zero to obtain the extremum, usually the minimum.

Consider two poles at -8 and +0.1 , one of them unstable. The resulting $\tau$ yields a command to shift to the left in the same way as if the pole were at -0.1 . This corresponds to $\tau \rightarrow \min$. Consider the shift result to $-0.08, \tau$ goes from negative high to a negative bigger value but $\tau$ continues reducing its size. Crossing the origin then $\tau$ would jump to positive high, the direction would keep all right.

The question is of interest when $\tau$ is a correct indicator. In the range of correct indicator, it is a simple scalar number, easily to be expressed with syms parameter for the state-space data. Eigenvalues, on the contrary, are always difficult to derive and to manipulate. Trend towards stability or danger is useful and possible even if it is not precise. Anyhow, in engineering systems in many cases one has to investigate additionally the numerical effort or computer-assisted simulation [2]. Well-established stability criteria are useful for checking stability of a given system. However, modifying to use for design facilities, the task of system stability often requires some additional efforts. A similar situation results in this connection.

Consider, e.g., a three-dimensional system $1 /[(a+j b)(a-j b) c]$. Then, $\tau$ is $2 a /\left(a^{2}+b^{2}\right)+1 / c$ and $2 a / b^{2}+1 / c$ for a small. The stability border is $a=0$, of course. If parameters of the system are changed in such a way that all the poles move towards the imaginary axis, the stability border is yet reached at $a=0$ and one has $\tau=2 \mathrm{a} / \mathrm{b}^{2}+1 / \mathrm{c}=1 / \mathrm{c}$. Smaller values of a show instability yet. The $\tau$-stability border is yet crossed at $\tau>1, \tau=0$ is not the stability border. For $\tau<1 / c$ the system is unstable all along, one eigenvalue is located in the right half-plane.

Trace of inverse matrix method is a good help to move the design activity towards stability increase or decrease. The correct ap-

Dieser Beitrag wurde außerhalb des Themenschwerpunkts dieses Heftes eingereicht

Weinmann, Alexander, Institute of Automation and Control, University of Technology, Gusshausstrasse 27-29/376, 1040 Vienna, Austria (E-mail: weinmann@acin.tuwien.ac.at) 


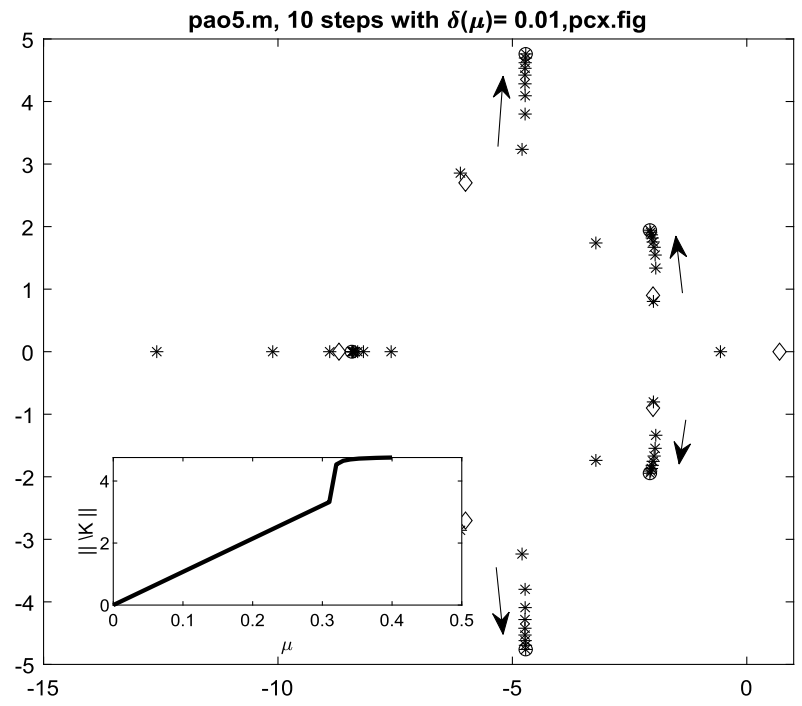

Fig. 1. Example 1 numerically solved. Diamonds indicate the eigenvalues of $A$ for the initial setup when starting the ten steps

proach has to be decided with additional considerations of physical or engineering domain. Hence, the result can be outlined as "extremum" $\left\{\operatorname{tr}\left[\mathbf{A}^{-1}\right]\right\}$ either max or min in a formula.

\section{Norm-oriented and stability-oriented $\tau$-locus}

Use is made of $\tau=-\operatorname{tr}\left[\mathbf{A}^{-1}\right]$ for the definitions of $\tau \triangleq$ [max or min] $\left\{-\operatorname{tr}\left[\mathbf{A}^{-1}\right]\right\}$ as an equality condition. Selection of a weighting parameter $\mu$ and the $\tau$-locus of corresponding eigenvalues yields an opportunity for valuating stability and control effort. Since $\tau$ is a replacement only, the advantages and disadvantages have to be rigorously investigated. Intending for $-\Sigma_{i} 1 / \lambda_{i}[\mathbf{A}+\mathbf{B K}] \rightarrow \min _{\mathbf{K}}$ including the norm as a condition, one has

$$
-\operatorname{tr}\left[(\mathbf{A}+\mathbf{B K})^{-1}\right]+\mu\|\mathbf{K}\|_{F}^{2} \rightarrow \min _{\mathbf{K}} .
$$

Differentiation $\frac{\partial}{\partial K}$ providing the minimum, using Eq. (13) and (17), yields

$$
\mathbf{B}^{T}(\mathbf{A}+\mathbf{B K})^{-2 T}+2 \mu \mathbf{K}=0
$$

for $\mu \neq 0$

Analytical solution is only possible for very low order, with respect to commonly having $\mathbf{A}$ and $\mathbf{A}^{T}$ in the same relation. With respect to the power -2 , solution is only possible in a numerical way.

The parameter $\mu$ is a factor in the $\tau$-locus, balancing the norm of $\mathbf{K}$ versus $\tau$ using their gradients. No single eigenvalues are considered.

The $\tau$-locus can also be used to represent the closed-loop eigenvalues $\lambda_{i}\left[\mathbf{A}_{c l}\right]$, different from $\lambda_{j}\left[\mathbf{A}_{c l}^{-1}\right]$. The $\tau$-characteristics as displayed in Fig. 1 are very different from the classical root loci. The characteristic starts at small $\mu$.

Example 1 Eq. (6) is solved numerically for an unstable system of order $n=6$, without executing a neglection and with ten $\Delta \mu$ steps $\lambda[\mathbf{A}(\mathbf{K}, \mu)]$. Figure 1 shows the result while increasing $\mu$ following the arrows, including a subplot norm of $\mathbf{K}$ versus $\mu$; or some alternative measure valuating the control effort for the current application.

To develop the example, having selected the initials for $\mu, \mathbf{K}$, and $\mathbf{A}$, find $\Delta \mathbf{K} \propto-\mathbf{B}^{T} \mathbf{A}^{-2 T} /(2 \mu)$, augment $\mathbf{K}$ with $\Delta \mathbf{K}$, get $\mathbf{A}:=\mathbf{A}+\mathbf{B K}$ and plot $\lambda[\mathbf{A}]$ for illustration, yielding Fig. 1.
Repeating the derivation leading to the previous section, now for the special case of output state controller, one finds $\mathbf{K}_{y}=-\mathbf{B}^{\top}(\mathbf{A}+$ $\left.\mathbf{B K}_{y} \mathbf{C}\right)^{-2 T} \mathbf{C}^{T} /(2 \mu)$

\section{Chordal projection}

The Trace of inverse matrix method yields the controller in closedloop state space depending on $\mu$. Chordal projection operates in frequency domain with scalar transfer functions $G(s)$ and $K^{-1}(s)$, not bold face, for $s=j \omega$ in the open loop. The quality is presented by the chordal stability margin $b_{G K}$ as the infimum versus $\omega$ of the chordal distance $\rho[G, K]=\delta\left[-K^{-1}, G\right]$. The straight distances between the chordal projections are the chordal distances $\rho(G, K)$ (see Fig. 2). Their minimum is $b_{G K}$ and provides the optimum $\mu$.

Example 2 In Fig. 2 the straight line distances between $G$ and $K$ are the basis for yielding $b_{G K}$, where $\min _{\omega}\left|G^{-1}\right|=\max _{\omega}|G|=$ $\|G\|_{\infty}$ was used,

$$
b_{G K}=\left[1+\left\|\frac{G(-s)-K(s)}{1+G(s) K(s)}\right\|_{\infty}^{2}\right]^{-1 / 2} .
$$

One tries to guarantee $b_{G K}>r_{G}$, the chordal uncertainty radius $[1,4]$. The chordal projection does not provide a design proposal for the controller. But chordal projection is used to improve the design approximation by $\tau$ in such a way that $\mu$ is selected observing $b_{G K}$ and/or satisfying the chordal uncertainty radius.

\section{Further applications}

\section{$4.1 \tau$-assignment}

Interested in assigning a desired $\Delta \tau_{e}$, from Eqs. (1) and (18) one finds

$$
\Delta \tau_{e}=-\Delta \operatorname{tr}\left[\mathbf{A}^{-1}\right]=\operatorname{tr}\left[\mathbf{A}^{-2} \mathbf{B} \Delta \mathbf{K}\right]
$$

Example 3 Defining $\mathbf{A}^{-2} \triangleq\left[f_{i, k}\right], \mathbf{B}=\left(\begin{array}{ll}0 & 1\end{array}\right)^{T}$, a multitude of solutions exists. Choosing the Frobenius norm $\|\Delta \mathbf{K}\|_{F} \triangleq\left\|\left(k_{1}, k_{2}\right)\right\|_{F} \rightarrow \min$, one has $k_{1 ; 2}=f_{2 ; 4} \Delta \tau_{e} /\left(f_{2}^{2}+f_{4}^{2}\right)$, denoted as Example 3.

\subsection{Advantageous diagnosis with uncertainty walk}

Useful diagnosis can be obtained by using the $\tau$-method. Consider, e.g., a continuous-time system of $n$-th order with $n$ parameters and distinct eigenvalues in the nominal case. Including uncertainties of the parameters at a specific closed cyclic (spherical) boundary, each eigenvalue moves along a closed route when displayed in the complex plane. This route is termed uncertainty walk. The uncertainty walks are different as far as the approximation to the instability border is concerned, or where the best opportunity exists for improving the performance quality.

Example 4 Using the $\tau$-method, the $n$ eigenvalues can be replaced roughly by $\tau$-values. The question arises and can be affirmed in many cases, if the $\tau$-value can be used to roughly replace the $n$ uncertainty routes by a single route of the $\tau$-value, or if at least a first diagnosis can be stated. In this example, these properties are displayed and illustrated in a 3D-plot (Fig. 3) or in an unwrapped display (Fig. 4).

\subsection{Numerical coefficients and pseudo inverse}

As a final application, consider a desired change in some dominant eigenvalues in magnitude $d$, which has to be performed by changes $\Delta \mathbf{K}$ of the state controller $\mathbf{K}$, see Eq. (9) and Eq. (11) 


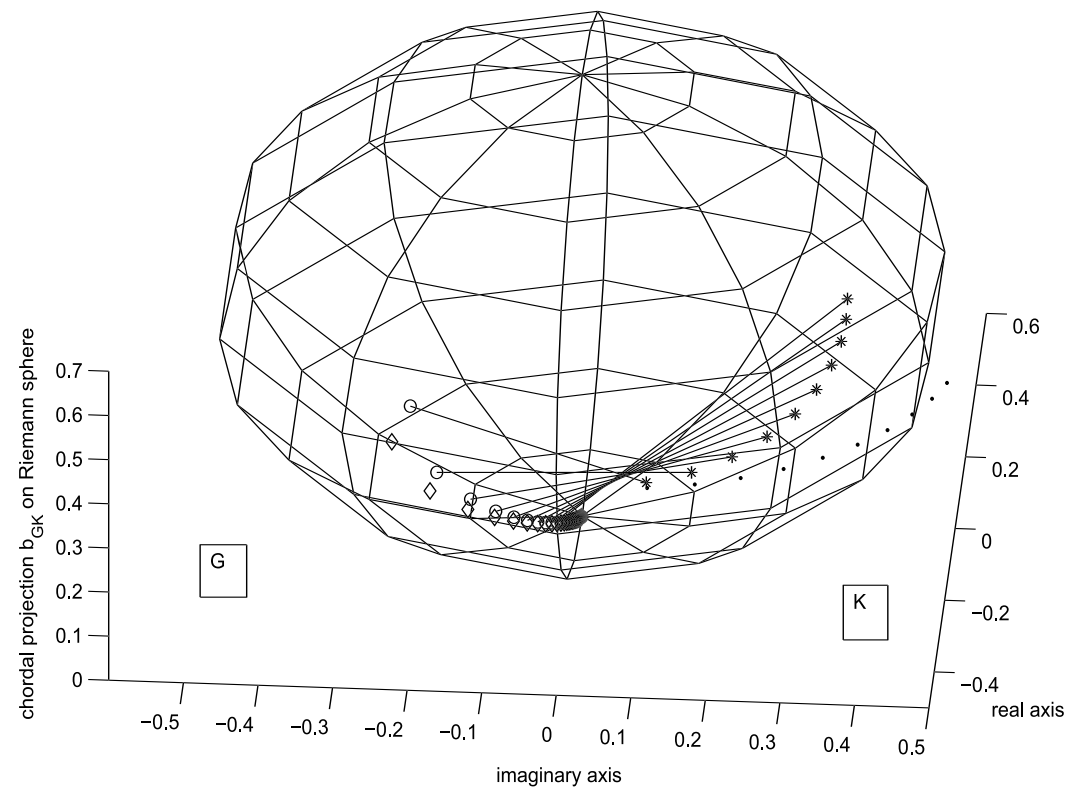

Fig. 2. Chordal projection on the Riemann sphere (Example 2)



Fig. 3. On top: uncertainty walk $\tau$, middle: complex plane, bottom: the most dangerous $\lambda_{i w}[\mathrm{~A}]$ (Example 4)

Using multiple differentiation with respect to $s$ yields the coefficients of powers of $s$ to compare the given and desired increments of some dominant eigenvalues with the unknown changes in the controller parameters.

If you were handicapped by numbers of 20 and more, you can start with comparison of replacing powers of $s$ by any numerical numbers of adequate height. Selecting small changes of eigenvalue increments and controller parameter increments you can use the Taylor expansion of the determinant. In Eq. (16) you simply use more comparisons of coefficients than necessary and you directly obtain the coefficients for the left pseudo-inverse matrix $\mathbf{M}^{\sharp L}$.

The incremental eigenvalue assignment adaptation is explained with a simple example. This, of course, is classical eigenvalue assignment, only Taylor expansion is unusual. Consider the system, e.g., with closed-loop equation

$$
\begin{aligned}
& (s+g)\left[(s+0.1)^{2}+9\right]-(s+g) \\
& \quad \times[(s+0.1+j 3+0.05+j 0.1)(s+0.1-j 3+0.05-j 0.1)+9] .
\end{aligned}
$$

You want to change the conjugate complex pole pair at e.g. $-1 \pm j 3$, such that it is moved to the left and towards the negative real axis with a quantity $d=-0.05 \pm j 0.1$. This change increment has to be provided by Eq. (16)

$$
\begin{aligned}
& \left(s-f_{1}\right)\left(s-f_{2}\right)\left(s-f_{3}\right)-\left(s-f_{1}\right)\left(s-f_{2}-d\right)\left(s-f_{3}-\operatorname{conj}(d)\right) \\
& \triangleq \operatorname{det}(s \mathbf{I}-\mathbf{A}-\mathbf{B K})-\operatorname{det}(s \mathbf{I}-\mathbf{A}-\mathbf{B K}-\mathbf{B} \Delta \mathbf{K})
\end{aligned}
$$




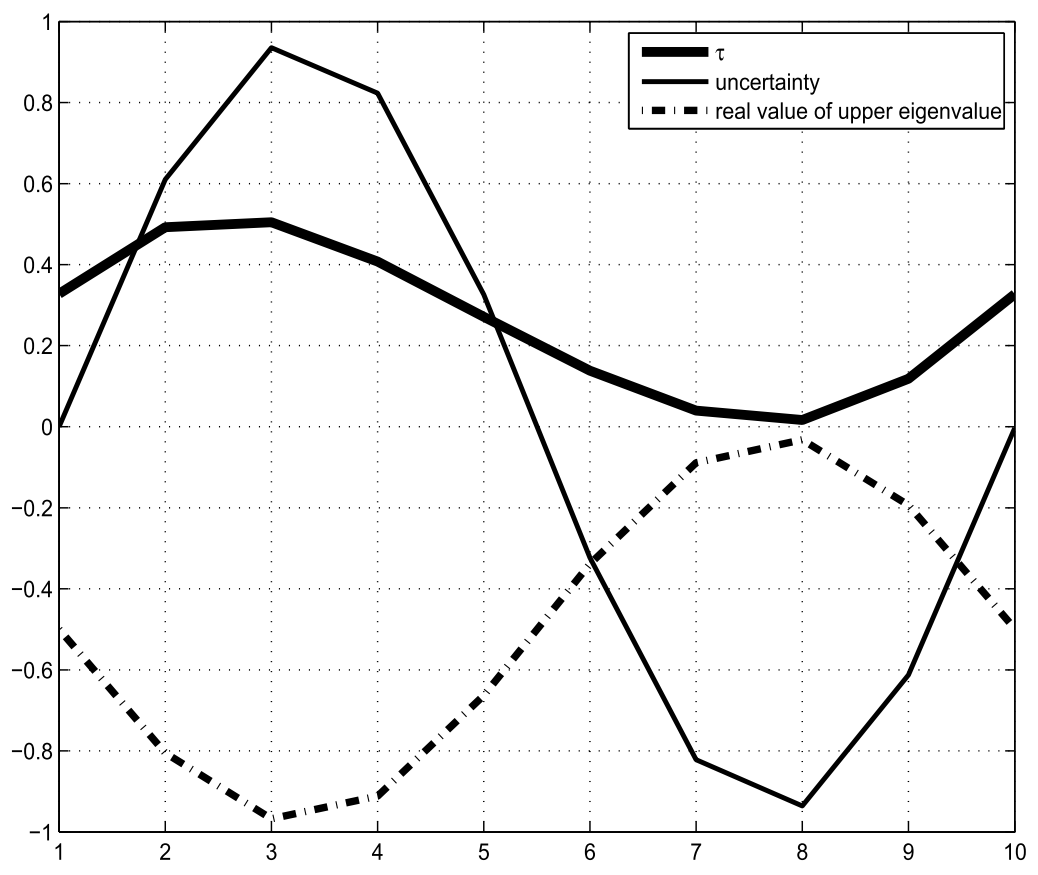

Fig. 4. Ten steps along the uncertainty walk unwrapped (Example 4)

$$
\stackrel{(16))}{=} \underbrace{\operatorname{col}\left[(\mathbf{S I}-\mathbf{A}-\mathbf{B K})^{-1}\right]^{T} \operatorname{det}(\mathbf{S I}-\mathbf{A}-\mathbf{B K})}_{[a a]} \cdot \underbrace{\operatorname{col}(\mathbf{B} \Delta \mathbf{K})}_{[b b]} .
$$

Use is made first by deriving the coefficients of the powers of $s$ by successive differentiation with respect to $s$, and second by stating the equations resulting from Eq. (10) equal to Eq. (12). Yielding G1, G2, G3 etc., and MATLAB $S=$ solve('G1', 'G2', 'G3' etc. ' $\triangle K 1$ ', ' $\Delta K 2^{\prime},{ }^{\prime} \Delta K 3^{\prime}$ etc.), the unknowns $\Delta K i$ are found. For small $\Delta \mathbf{K}$ the determinant is Taylor expanded in Eq. (16) using the adjoint. The set of equations Eq. (9) until Eq. (12) can be read for matrix variables $\mathbf{B} \Delta \mathbf{K}$ and for vector variable $\Delta K$.

If the comparison of the factors is performed by replacing $s$ by numerical values, there should be used more than three numerical values inserted. This is useful for applying pseudo inverse matrix.

In Line 10 substituting $s$ by a numerical value produces a vector $\mathbf{r} \in$ $\mathcal{R}^{q \times 1}$. In Line 12 the underbraced expression [aa] delivers a row $\mathbf{m} \in$ $\mathcal{R}^{1 \times 3}$ and $q$ times inserted a matrix $\mathbf{M} \in \mathcal{R}^{q \times 3}$. [bb] delivers a vector $\mathbf{v} \in \mathcal{R}^{3 \times 1}$. Thus we have $\mathbf{r}=\mathbf{M} \mathbf{v}$ which is usually overdetermined with respect to numerical uncertainties. Solving for the given data $\mathbf{r}$ and $\mathbf{M}$, one finds the unknown $\mathbf{v}=\left(\mathbf{M}^{T} \mathbf{M}\right)^{-1} \mathbf{M}^{T} \mathbf{r}=\mathbf{M}^{\sharp L} \mathbf{r}$.

\section{Conclusion}

Changing the set of inverse eigenvalues $\lambda_{j}\left[\mathbf{A}^{-1}\right]$ to $\tau$, the trace of the inverse, is a strong simplification with disadvantages and advantages. The latter is the opportunity of algebraic representation with syms variables, with an indicator for a simple setup. It has been discussed if this change is worth while. The item is how $\tau$ can substitute the eigenvalues and which advantages and problems arise.

The incremental small step eigenvalue assignment and its determinant Taylor expansion, not only for powers of $s$ but for numerical values, directly provides coefficients for the pseudo inverse matrix. The $\tau$-locus with the parameter $\mu$ valuates the magnitude of the controller norm for the purpose of direct control system design. The design result is also valuated by the stability margin of the chordal projection method.

In the case of uncertainty walk, the $\tau$-method provides a replacement of $\lambda_{i}$ by $\tau$.

Funding Note Open access funding provided by TU Wien (TUW).

Publisher's Note Springer Nature remains neutral with regard to jurisdictional claims in published maps and institutional affiliations.

Open Access Dieser Artikel wird unter der Creative Commons Namensnennung 4.0 International Lizenz veröffentlicht, welche die Nutzung, Vervielfältigung, Bearbeitung, Verbreitung und Wiedergabe in jeglichem Medium und Format erlaubt, sofern Sie den/die ursprünglichen Autor(en) und die Quelle ordnungsgemäß nennen, einen Link zur Creative Commons Lizenz beifügen und angeben, ob Änderungen vorgenommen wurden. Die in diesem Artikel enthaltenen Bilder und sonstiges Drittmaterial unterliegen ebenfalls der genannten Creative Commons Lizenz, sofern sich aus der Abbildungslegende nichts anderes ergibt. Sofern das betreffende Material nicht unter der genannten Creative Commons Lizenz steht und die betreffende Handlung nicht nach gesetzlichen Vorschriften erlaubt ist, ist für die oben aufgeführten Weiterverwendungen des Materials die Einwilligung des jeweiligen Rechteinhabers einzuholen. Weitere Details zur Lizenz entnehmen Sie bitte der Lizenzinformation auf http://creativecommons.org/licenses/by/4.0/deed.de.

\section{References}

1. Qiu, L., Zhou, K. (2013): Preclassical tools in postmodern control. IEEE Control Syst. Mag., 33(4), 26-38.

2. Ogata, K. (1970): Modern control engineering. 4th ed. Upper Saddle River: Prentice Hall.

3. Weinmann, A. (2001): Control system design based on holistic eigenvalue allocation. E\&l, Elektrotech. Inf., 118, 167-173.

4. Weinmann, A. (2017): Chordal automation towards high-order systems. E\&l, Elektrotech. Inf., 134, 276-281.

5. Weinmann, A. (2019): Influencing the oscillation properties of a control system. E\&I, Elektrotech. Inf., 136, 46-53. 


\section{Appendix}

$\mathbf{K} \in \mathcal{R}^{n \times n}$ for $\mathbf{x} \in \mathcal{R}^{n} .\|\mathbf{K}\|_{F}=+\sqrt{\operatorname{tr}\left[\mathbf{K}^{H} \mathbf{K}\right]}, \partial\|\mathbf{K}\|_{F}^{2} / \partial \mathbf{K}=2 \mathbf{K} . G^{\star}(j \omega)=$ $\operatorname{conj} G(j \omega)=\left.G(-s)\right|_{s=j \omega}$.

$$
\begin{gathered}
\frac{\partial \operatorname{tr}\left[\mathbf{U}^{-1}\right]}{\partial f}=-\operatorname{tr}\left[\mathbf{U}^{-2} \frac{\partial \mathbf{U}}{\partial f}\right] \\
\left.\operatorname{det}(\mathbf{A}+\Delta \mathbf{A})\right|_{\|\Delta \mathbf{A}\|_{F} \ll 1} \doteq \operatorname{det} \mathbf{A}+\sum_{i j}(\operatorname{adj} \mathbf{A})_{j i} \Delta A_{i j}
\end{gathered}
$$

\section{Author}

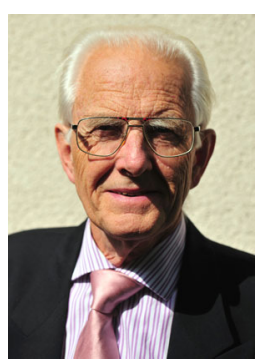

\section{Alexander Weinmann}

Born 1937 in Vienna, 1960: Dipl.-Ing., 1962:

Dr.techn., 1966: Habilitation "Elektrische

Antriebs- und Regelungstechnik", 1968-

2005: O. Univ. Prof. "Elektrische Regelungsund Steuerungstechnik" at Vienna University of Technology. Head of the Institute of Automatic Control 1968-2004. Long-term Dean of the Faculty of electrical engineering, coinitiating their foundation. Managing head of the former computing center of the entire university, chair of several commissions for academic administration, tuition and curriculum development.

$$
\begin{aligned}
& \doteq \operatorname{det} \mathbf{A}+\sum_{i j}\left[(\operatorname{adj} \mathbf{A})^{T} \cdot{ }^{*} \Delta \mathbf{A}\right]_{i j} \\
& \doteq \operatorname{det} \mathbf{A}+\left[\operatorname{col}\left(\operatorname{adj} \mathbf{A}^{T}\right)\right]^{T} \cdot \operatorname{col} \Delta \mathbf{A} . \\
& \frac{\partial}{\partial \mathbf{K}} \operatorname{tr}\left[(\mathbf{A}+\mathbf{B K})^{-1}\right]=-\mathbf{B}^{T}(\mathbf{A}+\mathbf{B K})^{-2 T} . \\
& \text { For } \quad \mathbf{A}_{c l} \triangleq \mathbf{A}+\mathbf{B} \mathbf{K}_{y} \mathbf{C}, \quad \frac{\partial}{\partial \mathbf{K}_{y}} \operatorname{tr}\left[\mathbf{A}_{c l}^{-1}\right]=-\left[\mathbf{C}\left(\mathbf{A}_{c l}\right)^{-2} \mathbf{B}\right]^{T} .
\end{aligned}
$$

He worked on various topics related to optimal control systems and design, identification, robustness, observers. Single author (without co-authorship) of roughly 140 scientific papers and seven books in several editions. 18 patents.

Consultant of ELIN with actual project responsibility, and other enterprises, up to 2006.

Editor and associate editor of several journals. Honor member OVE and ASCS. Among others: Awards Karoline and Guido Krafft, Kardinal Innitzer, Golden Stefan Medal of OVE, Rudolf Kompfner Medal of the Faculty of Electrical Engineering and Information Technology of Vienna University of Technology. Sports having staying-power. 